\title{
Teenagers and the risks of sexually transmitted diseases: a need for the provision of balanced information
}

\author{
Alex Mellanby, Fran Phelps, Clive Lawrence, John H Tripp
}

\begin{abstract}
Objective-Evaluation of teenagers' knowledge and understanding about sexually transmitted disease, conception and contraception.

Design-A questionnaire study.

Setting-Schools

Subjects-1025 teenagers aged 15/16 years

(mean 16.00).

Main outcome measures-Scores attained in response to questions about sexually transmitted disease related to the sources of information given as most helpful.

Results-Teenagers have an incorrect understanding of the risks of sexually transmitted diseases.

Conclusions-Teenagers may substantially underestimate their personal risk of contracting sexually transmitted diseases following the promotion of information about HIVIAIDS. Apparently simple messages about HIV and AIDS given in mass media advertising programmes may have unwanted results and need to be balanced by appropriate professional interpretation to teenagers.
\end{abstract}

\section{Introduction}

The increasing incidence of HIV and AIDS in the heterosexual population ${ }^{1}$ demonstrates an ineffectual response to the epidemic. The number of sexually active teenagers has been steadily increasing over the last 30 years. ${ }^{2-5}$ The pattern of young teenagers' sexual activity suggests a particular vulnerability to sexually transmitted diseases. This behaviour includes poor contraceptive use, ${ }^{67}$ multiple successive sexual partners, ${ }^{8}$ an inadequate concern about the risk of sexually transmitted disease, ${ }^{9}$ and poor knowledge of sexually transmitted disease other than HIV/AIDS. ${ }^{10}$ Young teenagers may not have sufficient cognitive skills to foresee risks in sexual relationships, ${ }^{11} 12$ and this may be compounded by unrealistic perceptions of themselves as relatively invulnerable. ${ }^{13}$ Evaluation of alterations in behaviours related to health suggest that without the personal appreciation of risk, behaviour tends not to change despite knowledge of possibility of harm. ${ }^{1415}$

As part of a study to evaluate the potential for increasing direct medical involvement in schools, we collected information from teenagers about their knowledge of sexually transmitted disease, reproduction and related subjects, and the sources of their information.
Subjects and methods

Teenagers aged from 15 to $16(\mathrm{~N}=1025)$ completed a questionnaire in nine schools in the South West of England. The questionnaires were supervised by members of the research team, and were conducted under "examination" conditions to prevent conferring. Sessions were about 70 minutes in length. The sample included students from both state and independent schools. Parental permission was sought for students to participate but only 10 were withdrawn from the sessions. The questions covered information about students' future expectations, their views on teenage relationships, knowledge of conception, contraception and sexually transmitted disease, and the sources of this information. There were five questions related to sexually transmitted disease, five related to contraception, and nine related to conception, pregnancy and related topics. One of the questions on sexually transmitted disease asked specifically if students were aware of "chlamydia"; this had been included for use in future assessment of our programme of education in the schools; we considered it unlikely that current students would be aware of this organism.

Students were asked to specify their sources of information on six topics, (facts about sexual intercourse, "periods", contraception, sexually transmitted disease, relationships, and morality), by identifying the "most helpful" and "next most helpful" from a list of nine choices including "none", or to indicate a source of their own under "other".

\section{Results}

Overall, on all the topics related to sex there were four main categories of sources of information specified "Most helpful" or "Next most helpful": $24 \%$ of boys and $18 \%$ of girls indicated "School", $26 \%$ of girls and $10 \%$ of boys indicated "Mother", $23 \%$ of girls and $18 \%$ of boys indicated "Friends", and $17 \%$ of boys and 9\% of girls indicated "T.V.". These results are similar to those found by Curtis et al. ${ }^{16}$

From the 1025 questionnaires five subjects gave no answers to all questions on sexually transmitted disease and 134 gave no answers on sources of information about this subject.

Table 1 shows the results from questions relating to sexually transmitted disease.

The sources of information regarded as "Most helpful" and "Next most helpful" on sexually transmitted disease are shown in fig 1. Television was specified either "Most helpful" or "Next most helpful" by $46 \%$ of the sample. School, television and books/magazines Dr A R Mellanby,

Health, Church Lane Exeter EX2 5SQ, UK

Accepted for publication 9 March 1992 
Table 1 Answers to questions relating to sexually transmitted diseases

\begin{tabular}{|c|c|c|c|c|c|c|}
\hline & \multicolumn{2}{|c|}{ Correct } & \multicolumn{2}{|c|}{ Incorrect } & \multicolumn{2}{|c|}{ Don't know } \\
\hline & $N$ & $\%$ & $N$ & $\%$ & $N$ & $\%$ \\
\hline $\begin{array}{l}\text { HIV/AIDS is the only sexually } \\
\text { transmitted disease that } \\
\text { cannot be cured }\end{array}$ & 450 & $44 \cdot 4$ & 334 & $32 \cdot 9$ & 230 & $22 \cdot 9$ \\
\hline $\begin{array}{l}\text { HIV/AIDS is the now the most } \\
\text { common sexually transmitted } \\
\text { disease }\end{array}$ & 242 & $24 \cdot 1$ & 533 & $53 \cdot 0$ & 231 & $23 \cdot 0$ \\
\hline $\begin{array}{l}\text { You can catch warts from sexual } \\
\text { intercourse }\end{array}$ & 304 & $30 \cdot 0$ & 297 & $29 \cdot 3$ & 414 & $40 \cdot 8$ \\
\hline $\begin{array}{l}\text { Using a condom during sexual } \\
\text { intercourse will give you total } \\
\text { protection against sexually } \\
\text { transmitted diseases }\end{array}$ & 341 & $33 \cdot 8$ & 569 & $56 \cdot 4$ & 98 & 9.7 \\
\hline $\begin{array}{l}\text { You can catch Chlamydia from } \\
\text { sexual intercourse }\end{array}$ & 79 & $7 \cdot 9$ & 41 & $4 \cdot 1$ & 884 & $86 \cdot 2$ \\
\hline
\end{tabular}

account for $84 \%$ of the specified "Most helpful" sources of information, with $27 \%$ of subjects stating television.

The answers to questions about sexually transmitted diseases were related to the source of information that students regarded as "most helpful". The results are shown in table 2 .

There are significant differences between the scores obtained in each group selected by "Most helpful" source of information. Those who specify " $T V$ " obtained significantly lower scores than either of the two other categories (Scheffe's test significant at $\mathrm{p}<0.01$ between both School and Books/magazines against T.V.). The mean score obtained on these questions by those who specified " $T$. $V$." as either "Most .." or "Next most helpful" $(-0.54)$ was significantly lower ( $t$ test for mean score difference $p<0.001$ ) than those who specified any other source of information (mean score 0.03 ).

The question on chlamydia was, predictably, beyond the knowledge of most respondents (84\% answered 'Don't know'). Completing the analysis with the remaining four questions on sexually transmitted diseases does not alter the finding that those specifying " $T$. $V$." as their most helpful source of information obtain the lowest scores (Scheffe's test significant at $p<$ 0.001 between both School and Books/magazines against T.V.)

From the whole sample 533 individuals (53\%) answered that HIV/AIDS is now the most common sexually transmitted disease. The results from this question are shown,

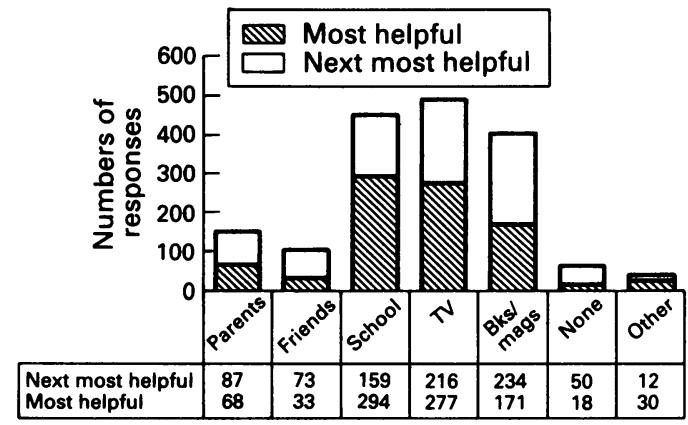

Figure 1 Sources of information on STDs specified most or next most helpful

divided by the specified sources of information on sexually transmitted disease, in table 3 .

Again the mean score for those who selected "T.V." as "Most helpful" is significantly lower than those who selected either "school" or

"books and magazines" (Scheffe's test significant at $p<0.01$ ). Similarly, those specifying "T.V." as either "Most ..." or "Next most helpful" scored significantly lower than those specifying any other source (" $T$. $V$." mean score -0.37 , any other source $-0.11, t$ test significant at $p<0.001$ ).

It is possible that those selecting television as a source of information may be a group that differ in other ways from the rest of the sample. Discriminant analysis did not show any relationship between sources of information and social class, Socio-economic group, or planned duration of education. Although there were significantly (chi square $=42.48, p<0.001$ ) more females in the group that specified "Books/magazines" in the most helpful category, there were no overall differences between the sexes on their scores on questions related to sexually transmitted diseases.

The number of General Certificate of Secondary Education (GCSE) examinations that students were planning to take (which they would have sat in the term following the questionnaire) were associated with the number of correct answers, and the results are shown in table 4.

Thus students expecting to take nine or more GCSEs score significantly higher than those planning to take fewer GCSEs (Scheffe's

Table 2 STD question responses and specified source of information

\begin{tabular}{|c|c|c|c|c|c|c|c|c|}
\hline \multirow[b]{2}{*}{ Source } & \multicolumn{2}{|c|}{ Correct answers } & \multicolumn{2}{|c|}{ Incorrect answers } & \multicolumn{2}{|c|}{ Don't know } & \multirow{2}{*}{$\begin{array}{l}\text { Mean } \\
\text { score }\end{array}$} & \multirow{2}{*}{$\begin{array}{l}95 \% \text { confidence limits } \\
\text { for mean score }\end{array}$} \\
\hline & $N$ & $\%$ & $N$ & $\%$ & $N$ & $\%$ & & \\
\hline $\begin{array}{l}\text { Books/mags. } \\
\text { School } \\
\text { TV. }\end{array}$ & $\begin{array}{l}286 \\
434 \\
321\end{array}$ & $\begin{array}{l}33 \cdot 69 \\
29 \cdot 69 \\
23.33\end{array}$ & $\begin{array}{l}265 \\
466 \\
528\end{array}$ & $\begin{array}{l}31 \cdot 21 \\
31 \cdot 87 \\
38 \cdot 37\end{array}$ & $\begin{array}{l}298 \\
562 \\
527\end{array}$ & $\begin{array}{l}35 \cdot 10 \\
38 \cdot 44 \\
38 \cdot 29\end{array}$ & $\begin{array}{r}0.06 \\
-0.13 \\
-0.73\end{array}$ & $\begin{array}{l}-0.27 \text { to } 0.39 \\
-0.36 \text { to } 0.09 \\
-0.95 \text { to }-0.51\end{array}$ \\
\hline
\end{tabular}

Mean scores are calculated by assigning +1 to a correct answer, -1 to an incorrect answer, and 0 for don't know. The scores range from +5 to -5 for the five STD questions.

Table 3 Responses to the question "HIVIAIDS is now the most common sexually transmitted disease" by specified source of information

\begin{tabular}{|c|c|c|c|c|c|c|c|c|}
\hline \multirow[b]{2}{*}{ Source } & \multicolumn{2}{|c|}{ Correct answers } & \multicolumn{2}{|c|}{ Incorrect answers } & \multicolumn{2}{|c|}{ Don't know } & \multirow{2}{*}{$\begin{array}{l}\text { Mean } \\
\text { score }\end{array}$} & \multirow{2}{*}{$\begin{array}{l}95 \% \text { confidence limits } \\
\text { for mean score }\end{array}$} \\
\hline & $N$ & $\%$ & $N$ & $\%$ & $N$ & $\%$ & & \\
\hline $\begin{array}{l}\text { Books/mags. } \\
\text { School } \\
\text { TV. }\end{array}$ & $\begin{array}{l}58 \\
84 \\
43\end{array}$ & $\begin{array}{l}33 \cdot 90 \\
28 \cdot 60 \\
15 \cdot 50\end{array}$ & $\begin{array}{r}71 \\
124 \\
169\end{array}$ & $\begin{array}{l}41 \cdot 50 \\
42 \cdot 20 \\
61 \cdot 00\end{array}$ & $\begin{array}{l}41 \\
82 \\
64\end{array}$ & $\begin{array}{l}24 \cdot 00 \\
27 \cdot 90 \\
23 \cdot 10\end{array}$ & $\begin{array}{l}-0.08 \\
-0.14 \\
-0.46\end{array}$ & $\begin{array}{l}-0.21 \text { to } 0.06 \\
-0.23 \text { to }-0.04 \\
-0.55 \text { to }-0.37\end{array}$ \\
\hline
\end{tabular}


Table 4 Responses to questions on STDs and proposed number of GCSEs

\begin{tabular}{llll}
\hline Number of GCSEs & Number of teenagers & Mean score & $\begin{array}{l}95 \% \text { confidence limits for } \\
\text { mean score }\end{array}$ \\
\hline $0-4$ & 58 & -1.00 & -1.55 to -0.45 \\
$5-8$ & 465 & -0.67 & -0.84 to -0.50 \\
$9+$ & 431 & 0.07 & -0.11 to 0.24 \\
\hline
\end{tabular}

Table 5 Answers to questions on contraception and sources of information about contraception

\begin{tabular}{llll}
\hline Source & $N$ & Mean score & $\begin{array}{l}95 \% \text { confidence limits for } \\
\text { mean scores }\end{array}$ \\
\hline Books/mags. & 181 & 1.86 & 1.58 to 2.14 \\
School & 272 & 1.82 & 1.60 to 2.03 \\
Parent & 129 & 1.78 & 1.40 to 2.15 \\
Friends & 145 & 1.55 & 1.24 to 1.86 \\
T.V. & 98 & 1.00 & 0.59 to 1.41 \\
\hline
\end{tabular}

Mean scores are calculated by assigning +1 to a correct answer, -1 to an incorrect answer and 0 for don't know. The scores range from +5 to -5 for the five questions on contraception.

test for differences of the mean scores significant at $\mathrm{p}<0.01$ ).

There were no differences between the groups defined by GCSE number and their specified source of information on sexually transmitted diseases.

To compare results on sexually transmitted diseases, the number of correct answers to the questions on contraception were related to the sources of information stated for this subject. In this case there were five main specified sources of information as shown in figure 2.

Table 5 gives the results of the scores on the contraception questions related to the five main categories of sources of information.

Again those selecting "T.V." as the "Most helpful" source of information had lower scores than those selecting either "school" or "Books/ magazines" (Scheffe's test for difference in mean score significant at $p<0.05$ ). This also applies for those selecting "T. $V$ "' as either "Most .." or "Next most helpful" (mean score for "T.V." 1.27, other sources 1.90, $t$ test significant at $\mathrm{p}<0.001)$. There were no significant differences in the mean scores obtained by those who specified "Parents" or "Friends" from any other group. As with the sexually transmitted disease questions, those specifying "T.V." had the lowest overall score.

There were no associations between high or low scores and the specified sources of information for nine other questions relating to general topics related to sex.

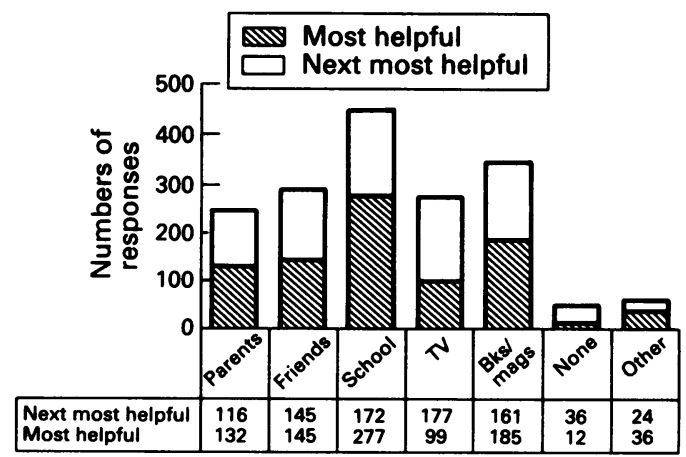

Figure 2 Sources of information on contraception specified most or next most helpful

\section{Discussion}

Television was the most frequently cited source of "Most helpful" or "Next most helpful" information on sexually transmitted diseases (by 475 of the 1025 teenagers in this questionnaire survey). Television was second only to "School" as the "Most helpful" specified source of information (29\% of responses for "School" and $27 \%$ for " $T . V$. "). The prominence of television may well reflect the attention given to sexually transmitted diseases since the advent of the HIV epidemic.

Television accounted for $16 \%$ of sources cited as "Most helpful" information on contraception and $7 \%$ on general topics about reproduction, relationships, and morality. For these subjects "Mother" was the most frequently specified source for girls (35\%), and "School" for boys (27\%), with "Friends" ranked second for both (32\% for girls, $25 \%$ for boys). Again television programmes have been active in giving information about condoms, which could account for television's prominence as a source of information on contraception. Teenagers appear to have found television less helpful on the basic facts of reproduction, relationships, or morality.

It is possible that "School" might cover several sources of information within the school. The fact that the proportion of students identifying "School" as their most helpful source of information ranged from $4 \%$ to $34 \%$ in different schools suggests that students who specify "School" are identifying information supplied formally and dependent on the variation of the school's approach towards sex education.

Only $28 \%$ of answers to the five questions related to sexually transmitted diseases were correct. A higher proportion of correct responses was attained on the questions related to contraception ( $59 \%$ correct), and the other general questions ( $48 \%$ correct). Those specifying television as "Most helpful" achieved the lowest scores for the questions on sexually transmitted disease and contraception. There were no significant differences on scores for the questions on general sexual knowledge and specified sources of information.

The questions most frequently answered incorrectly were, first, a belief that condoms give total protection against sexually transmitted diseases ( $56 \%$ incorrect), and second, that HIV/AIDS is now the commonest sexually transmitted disease (53\% incorrect).

In view of the high profile given to HIV/ AIDS and "safe(r) sex" it is perhaps understandable that teenagers should have this subject in the forefront of their minds and hence consider HIV/AIDS to be the commonest sexually transmitted disease. Indeed it is an indication of the success of campaigns about HIV and AIDS, especially on television, that students have been made aware of these issues. Arguably, this has been at the expense of accuracy, since those who specify television as their "Most helpful" source of information attain significantly lower scores on these two questions than those who specify any other source of information ( $t$ test for mean score 
differences significant at $\mathrm{p}<0.001$ ).

There were also twice as many incorrect answers on contraception generated from the group specifying television as "Most helpful" compared with those specifying other sources of information. This may suggest that it is the medium of transmission rather than the subject that is responsible for the high number of incorrect answers.

One possible conclusion which can be drawn from these results is that television, whilst promoting information about HIV and AIDS, has not been able to provide a balance of information on other sexually transmitted diseases or accurate information about the protective capabilities of condoms.

The teenagers' answers provide evidence for this lack of balance since $66 \%$ of respondents correctly identified that condoms do not give total protection against pregnancy, but only $33 \%$ correctly identified that they do not give total protection against sexually transmitted diseases.

Previous investigations of teenagers from schools within our sample indicated that $23 \%$ of boys and $25 \%$ of girls were sexually active at age 16 years. This rose to $39 \%$ of boys and $47 \%$ of girls who had experienced a "steady" relationship, defined by the teenagers as a "monogamous" relationship becoming "steady" after a variable period of about 8-10 weeks.

Will teenagers' understanding of these subjects affect their risk of contracting sexually transmitted disease? Currently few teenagers have personal knowledge of individuals with HIV infection or AIDS. This reduces their perception of personal risk, a major factor in altering behaviour, ${ }^{14}$ and may partially account for their low use of protective contraception. ${ }^{10}$ It is also consistent with the finding that teenagers have not apparently altered their behaviour as a result of the AIDS epidemic. ${ }^{910}$ If they believe that HIV is the commonest sexually transmitted disease, this is something they consider as outside their own experience and thus rare; it is then unlikely that teenagers will consider other sexually transmitted diseases a threat. This is evidenced by the increasing numbers of teenagers with problems related to sexually transmitted diseases. ${ }^{17}$

The results from this questionnaire study demonstrate that teenagers who find "School" or "Books/magazines" to be a helpful source of information achieve a better understanding of the subject. Although there is considerable room for improvement, this does suggest that providing information to teenagers about health can be effective when carried out in school.

This is not a simple task, though one that is sometimes devolved to teaching and medical staff who may have had no specific undergraduate or postgraduate training in this area. Analysis of intervention studies in schools reveals that didactic, formal teaching about health risks, while increasing knowledge, has little or no effect or, in some cases, an adverse effect on behaviour, whereas several innovative programmes have had considerable and positive benefits. ${ }^{18}$

There are few doctors who have had training in innovative methods of teaching, especially to large classes of adolescents. Teachers, who may have the necessary skills and training, are likely to find difficulty in gaining access to relevant and current medical data. We believe that there is considerable scope for closer cooperation between the medical and teaching professions, not merely to develop educational strategies, but to ensure that effective messages are delivered in the classroom. This could, at least, redress the balance in the information currently given to teenagers about sexually transmitted diseases from other sources, and, at best, might reduce their risk of contracting such diseases.

We thank the students and staff of all the schools for their cooperation. This study was funded by the South Western cooperation. This study was

1 Communicable Disease Reports. AIDS and HIV-1 antibody reports-United Kingdom. 1991;1:15;67-8.

Schofield M. The Sexual behaviour of young people. Longman 1965.

3 Farrell C. My mother myself... London:Routledge Kegan Paul 1978 .

4 Ford N. Urban-rural variations in the level of heterosexual activity of young people. Area 1989;21:237-48.

5 Curtis $\mathrm{H}$, Lawrence C, Tripp J.Teenage sexuality: implications for controlling AIDS. Arch Dis Child $1989 ; 64 ; 1240-5$

6 Zelnik M, Shah FK. First Intercourse among young Americans. Family Planning Perspectives 1983; 15:2;64-70.

7 Curtis HA, Lawrence CJ, Tripp JH. Teenage sexual intercourse and pregnancy. Arch Dis Child 1988;63:373-9.

8 Zylke JW, Adolescents and HIV and AIDS. $\Im A M A$ 1989;262:16;2197.

9 Clarke J, Abram R, Monteiro EF. The sexual behaviour and knowledge about AIDS in a group of young adolescent girls in Leeds. Genitourin Med 1990;66:189-92.

10 Ford N. A Survey of the AIDS Awareness and Sexua Behaviour and Attitudes of Young People in Bristol. Institute of Population Studies report September 1988.

11 CoblinerWG Prency in the Single Adolescent Girl: The role of Cognitive Functions. $f$ Youth Adolesc 1974;3:17-29.

12 Blum RW, Resnick MD. Adolescent Sexual Decision Making:Contraception, Pregnancy, Abortion, MotherMaking:Contraception, Pregnancy, Abo

13 Moore S, Rosenthal D. Adolescent Invulnerability and Perceptions of AIDS Risk. fournal of Adolescent Research 1991;6:164-80.

14 Maccoby N, Farquhar JW, Wood PD, Alexander J. Reducing the Risk Of Cardiovascular Disease: Effects of a community-based Campaign on knowledge and behavior. Fournal of Community Health 1977;3:100-14.

15 Stout JW, Rivara FP. Schools and Sex Education: Does it Work? Pediatrics $1989 ; 83: 375-9$.

16 Curtis HA, Tripp JH, Lawrence C, Clarke WL. Teenage relationships and sex education. Arch Dis Child 1988;63:935-41.

17 Donovan C. Adolescent sexuality. BMF 1990;300:1026-7.

18 Rundall TG, Bruvold WH. A Meta-analysis of School-based Smoking and Alcohol use prevention programs. Health Education Quartely 1988;15:317-34. 